\title{
Epidemiological update on prevalence and incidence of overweight and obesity in adults in the south-east of the Islamic Republic of Iran: findings from the Kerman Coronary Artery Diseases Risk Factors Study (KERCADRS)
}

Hamid Najafipour, ${ }^{1}$ Mehdi Bagheri, ${ }^{2}$ Shadan Saberi, ${ }^{3}$ Mitra Farokhi, ${ }^{4}$ Raheleh Amirzadeh ${ }^{5}$ and Ali Mirzazadeh ${ }^{6}$

${ }^{1}$ Cardiovascular Research Center, Institute of Basic and Clinical Physiology Sciences, Kerman University of Medical Sciences, Kerman, Islamic Republic of Iran. (Correspondence to: M. Bagheri: mehdi_b_ped@yahoo.com). ${ }^{2}$ Cardiovascular Research Center and Department of Cardiology, Afzalipour Medical Faculty, Shafa Hospital, Kerman, Islamic Republic of Iran. ${ }^{3}$ Physiology Research Center, Institute of Neuropharmacology, Kerman University of Medical Sciences, Kerman, Islamic Republic of Iran. ${ }^{4}$ Endocrinology and Metabolism Research Center, Institute of Basic and Clinical Physiology Sciences, Kerman University of Medical Sciences, Kerman, Islamic Republic of Iran. ${ }^{5}$ Social Determinants of Health Research Center, Institute for Futures Studies in Health, Kerman University of Medical Sciences, Kerman, Islamic Republic of Iran. ${ }^{6}$ Department of Epidemiology and Biostatistics, University of California San Francisco, California, United States of America.

\begin{abstract}
Background: Obesity is common worldwide, especially in low- and middle-income countries.

Aims: To update data on the prevalence of overweight, obesity and central obesity, and to measure incidence rates for such outcomes in adults living in the south-east of the Islamic Republic of Iran.

Methods: We enrolled 9997 adults (aged 15-80 years) between 2014 and 2018 (phase 2); 2820 of whom had participated in phase 1 (2009-2011). Participants were examined for overweight, obesity, central obesity, diabetes, hypertension, low physical activity, and dyslipidaemia. Univariate and multivariate logistic regression models were used to determine the potential predictors of overweight, obesity and central obesity, and adjusted odds ratios (AOR) were obtained. Incidence rate of overweight, obesity and central obesity was reported among those who had none of these outcomes in phase 1.

Results: The prevalence was 35.8\% (37\% men, 35\% women) for overweight, $22.3 \%$ (16\% men, $26.3 \%$ women) for obesity, and $31.1 \%$ (15.6\% men, $41.2 \%$ women) for central obesity. The prevalence of overweight/obesity was significantly associated with age $(\mathrm{AOR}=2.8-7.4)$, higher education $(\mathrm{AOR}=1.7)$, female gender $(\mathrm{AOR}=1.4)$, low physical activity $(\mathrm{AOR}=1.3)$, smoking $(\mathrm{AOR}=0.55)$ and opium use $(\mathrm{AOR}=0.79)$. The prevalence increased from $33.3 \%$ to $35.8 \%$ for overweight and from $15.4 \%$ to $22.3 \%$ for obesity between phases 1 and 2 . The incidence rate per 100 person-years was 5.5 for overweight, 4.7 for obesity and 2.9 for central obesity.

Conclusion: Prevalence of overweight and obesity increased over 5 years. Middle-aged participants, women, and those with low physical activity were at higher risk for overweight/obesity.

Keywords: overweight, obesity, risk factors, prevalence, incidence

Citation: Najafipour H; Bagheri M; Saberi S; Farokhi M; Amirzadeh R; Mirzazadeh A. Epidemiological update on prevalence and incidence of overweight and obesity in adults in the south-east of the Islamic Republic of Iran: findings from the Kerman Coronary Artery Diseases Risk FActors Study (KERCADRS). East Mediterr Health J. 2021;27(9):874-883. https://doi.org/10.26719/emhj.21.035

Received: 15/06/20; accepted: 04/02/21

Copyright ( ) World Health Organization (WHO) 2021. Open Access. Some rights reserved. This work is available under the CC BY-NC-SA 3.0 IGO license (https://creativecommons.org/licenses/by-nc-sa/3.o/igo)
\end{abstract}

\section{Introduction}

Abnormal body mass index (BMI), which can be in the form of overweight and obesity, has been one of the greatest health challenges worldwide. Recent studies have indicated that the worldwide prevalence of obesity nearly tripled between 1975 and 2016 (1,2). Obesity has been associated with many diseases such as type 2 diabetes mellitus, cardiovascular disease (CVD), hypertension, and cancer (3). According to the World Health Organization (WHO) in $2018, \sim 13 \%$ of the global adult population was obese in 2016 (4). The problem of obesity affects many Asian and Persian Gulf countries, especially the Islamic Republic of Iran, and it has become one of the top health challenges in such countries $(5,6)$. WHO has also reported that the prevalence of overweight and obesity in Middle East countries is $54.2 \%$ in women and $31.4 \%$ in men $(7,8)$. Studies in the Islamic Republic of Iran have shown the upward trend in obesity prevalence in all age groups > 15 years $(9-11)$. Due to the plentiful differences in sociocultural issues in all Iranian provinces, and considerable variations in lifestyle and dietary/nutritional culture, a varied pattern of overweight and obesity prevalence has been observed in recent years. A systematic review revealed a prevalence of overweight between $27 \%$ and $38.5 \%$ and a prevalence of obesity between $12.6 \%$ and $25.9 \%$ (12). To our knowledge, there is little information about the prevalence of obesity and overweight and their predictors in Southeastern Iran. In a population-based study (Kerman Coronary Artery Disease Risk Factors Study; 
KERCADRS) conducted from 2009 to 2011 on 5900 adults aged 15-75 years, the prevalence of overweight and obesity was $29.6 \%$ (29.5\% men, $29.7 \%$ women) and $13.0 \%$ (9.3\% men, $16.9 \%$ women), respectively (13).

The present study is the second phase of KERCADRS conducted on a larger sample size of 9997 individuals from 2014 to 2018 . The study had 2 main objectives: (1) to determine the prevalence and predictors of overweight and obesity, and their affecting factors [e.g., level of physical activity, anxiety, depression, cigarette smoking, and opium addiction] in the population aged 15 -80 years; and (2) to compare the findings of the second phase with the first phase (2009-2011) to explore the incidence rate and trend in changes in prevalence of overweight and obesity. This will provide a better insight into the severity and growth rate of these two important CVD risk factors in this region in the past 5 years.

\section{Methods}

\section{Study design}

This was a serial cross-sectional study that recruited participants in two phases (2014-2018 and 2009-2011) and was conducted according to the Declaration of Helsinki. The study protocols were approved by the Ethics Committee of Kerman University of Medical Sciences (ethics code: IR.KMU.REC.1392.405). Written informed consent was obtained from all subjects.

\section{Study population}

Phase 2 of KERCADRS was conducted from 2014 to 2018 on 9997 adults aged 15-80 years in Kerman, the largest city in Southeastern Iran. Kerman is the capital city of Kerman Province with a population of $\sim 750000$ and is located $\sim 1000 \mathrm{~km}$ from the capital, Tehran. People are mostly busy with white-collar jobs in the government sector, agriculture, and trade. Lifestyle patterns are typically aggregated in families. The methodology and more detailed description of the selected variables have been published elsewhere (14). We used a non-proportional-to-size one-stage cluster sampling household survey, and randomly selected 420 zip codes, each representing a house (called a seed). Social mobilizers approached the seed household and invited all eligible people to participate in the study. Recruitment was continued until 24 persons were recruited in each cluster and an overall target sample size of close to 10000 was achieved.

\section{Data collection}

The study participants were examined by a physician for various coronary artery disease (CAD) risk factors using a standard structured questionnaire (14). The questionnaire consisted of sociodemographic data; level of education [1, illiterate; 2 , primary to high school; and 3 , above high school (college level)]; cigarette smoking (1, never smoked; 2 , current smoker); and opium use [1, nonuser; 2, occasional user, and 3, dependent (continuous use)]. Level of depression and anxiety were assessed using the
Beck Depression Inventory and Beck Anxiety Inventory, respectively. For depression, scores $>30$ and for anxiety, scores $>26$ were identified as disease states (14). The Global Physical Activity Questionnaire was used to evaluate the level of physical activity. The total metabolic equivalent of task (MET) was calculated for the status of activity in work-, transport- and recreation-related physical activity. MET is the rate of energy used by a person while sitting. Moderate physical activity is considered as consuming energy $>4$ times, and high physical activity is energy consumption $>8$ times the energy used while sitting (15).

\section{Measurements}

Height, weight and waist circumference (WC) were measured by standard methods (14). WC $>88 \mathrm{~cm}$ for women and $>102 \mathrm{~cm}$ for men was considered as central obesity. Height was measured in standing position without shoes, and weight was measured by a standard weighing balance (Seca, Hamburg, Germany). BMI was classified as normal $\left(18.5-24.9 \mathrm{~kg} / \mathrm{m}^{2}\right)$, overweight $(25-$ $\left.29.9 \mathrm{~kg} / \mathrm{m}^{2}\right)$ and obese $\left(\geq 30 \mathrm{~kg} / \mathrm{m}^{2}\right)$. Laboratory measurements (10-12 hours of fasting) included fasting plasma glucose, triglyceride and total cholesterol. Cholesterol and triglyceride values $>200 \mathrm{mg} / \mathrm{dl}$ were considered abnormal. All individuals with previously diagnosed diabetes, taking insulin or antidiabetic drugs, or with fasting plasma glucose $\geq 126 \mathrm{mg} / \mathrm{dl}$ were considered to have diabetes. Blood pressure was measured with a standard mercury manometer (Richter, Speichersdorf, Germany). All individuals with previously diagnosed hypertension, taking antihypertensive drugs, or with resting systolic/ diastolic blood pressure $\geq 140 / 90 \mathrm{mmHg}$ were considered to have hypertension.

\section{Incidence of overweight/obesity}

We used the same method to calculate the incidence rate of overweight, obesity and central obesity. Therefore, we only present the method for calculation of incidence rate of overweight. To calculate the incidence rate of overweight, we used data from those who participated in both study phases, and who had normal BMI in phase 1 , and therefore, were at the risk of becoming overweight during follow-up (Supplementary Figure 1). Therefore, 48.7\% of the 5900 participants ( 2873 cases) in phase 1 who were already overweight were excluded from calculation of incidence rate. Out of the remaining 3027 participants, 207 $(6.8 \%)$ were lost to follow-up. The number of new overweight cases (among the 3027 cases) identified during the follow-up period was designated the numerator. For those who had normal BMI in phase 1, the time difference (in years) between the visits in phases 1 and 2 was calculated as person-years at risk. Therefore, the denominator was the sum of the time each person was followed (person-year), totalled for all 3027 persons who were at risk of becoming overweight. For those who were lost to follow-up, we assumed that they had followed up for an average 2.5 years (half of the overall follow-up time be- 
tween phases 1 and 2), and were then lost to follow-up. Incidence rate was calculated using the formula (16):

Number of new cases of overweight during 5 years

Incidence rate $=$ $\mathrm{x} 100$

Total person-years for all persons at risk

\section{Statistical analysis}

Numerical variables were described as mean and standard deviation and categorical/ordinal variables as $\mathrm{n}(\%)$. Data management and all statistical analyses were conducted using STATA version 14. Data were analysed using the survey data analysis package. To account for the clustering effect, we used the survey data package analysis, in which we set clusters as the primary sampling units. Because of the non-proportionate-to-size sampling method, the total estimates were standardized based on the real age distribution of the target population (national census of Kerman population size in 2016). We reported weighted prevalence (17) for overweight, obesity and central obesity. We ran the bivariate analysis to assess the association between all covariates and the study outcome (overweight, obesity and central obesity binary outcomes), one at a time. We included all covariates with $\mathrm{P}<$ 0.05 in the multivariate logistic regression. Outputs from univariate and multivariate survey logistic regression were reported as crude and adjusted odds ratios (AORs). Data from phase 2 of the study were used in the logistic regression.

\section{Results}

\section{Overweight, obesity and central obesity}

Overall mean BMI was $27 \mathrm{~kg} / \mathrm{m}^{2}$ in phase 2 (Supplementary Table 1), which was higher than $25.6 \mathrm{~kg} / \mathrm{m}^{2}$ obtained in phase 1 (Figure $1 \mathrm{~A}$ ). Overall mean WC was $89.8 \mathrm{~cm}$ in phase 2, which was also higher than $85 \mathrm{~cm}$ obtained in phase 1 (Figure $1 \mathrm{~B}$ ). BMI and WC, overall and for both genders, were significantly higher in phase 2 than in phase $1(\mathrm{P}<0.001)$. In phase 2 , mean BMI was $23.1 \mathrm{~kg} /$ $\mathrm{m}^{2}$ among those aged 15-24 years and reached $28.2 \mathrm{~kg} /$ $\mathrm{m}^{2}$ among those aged $45-54$ years (Figure $1 \mathrm{C}$ ). The corresponding values were both lower in the same age groups in phase 1 . In phase 2 , mean WC was $77.4 \mathrm{~cm}$ among those aged 15-24 years and reached $94.3 \mathrm{~cm}$ among those aged 55-64 years (Figure 1D). These values were also lower in the same age groups in phase 1.

The overall prevalence of overweight and obesity was $35.8 \%$ and $22.3 \%$, respectively (Table 1 ), whereas the corresponding values in phase 1 were $33.3 \%$ and $15.4 \%$, respectively (Figure 2 ). The prevalence of central obesity was $31.1 \%$ in phase 2 (Table 1 ) and $18.2 \%$ in phase 1 (Figure 2). All three variables, overall and in each gender, were significantly higher in phase 2 than in phase 1 . The overweight prevalence increased from $15.5 \%$ (phase 1) and $20.6 \%$ (phase 2 ) in subjects aged $15-24$ years to peaks at $43.2 \%$ (phase 1) among those aged 35-44 years and $42.6 \%$ (phase 2) among those aged 45-54 years (Figure 2D).
Obesity among the first age group was 5.1\% (phase 1) and $10.3 \%$ (phase 2 ), which significantly increased with age to a maximum of $25.8 \%$ (phase 1) among those aged 45-54 years and $31.0 \%$ (phase 2) among those aged 55-64 years (Figure 2E). Both obesity and central obesity were higher in all age groups in phase 2 compared with the same values in phase 1 .

The prevalence of obesity and central obesity showed a decreasing trend with education and cigarette smoking and in dependent opium users (Table 1). Depression and anxiety had almost no significant effect. People with higher physical activity had a lower prevalence of overweight, obesity and central obesity.

\section{Predictors of abnormal BMI and WC}

The odds of combined overweight and obesity significantly increased with age, in people with hypertension, patients with diabetes, higher education levels, female gender, and those with low physical activity (Table 1). Conversely, AOR for overweight/obesity significantly decreased among cigarette smokers, opium users and those with depression. In terms of central obesity, AOR of abnormal WC showed a trend similar to overweight/ obesity. The corresponding results for phase 1 showed that AOR for overweight/obesity significantly increased with age, education level, lower physical activity and female gender (13).

\section{Comorbidities with overweight and obesity}

On the whole, with increasing BMI, the prevalence of diabetes mellitus increased from $9.1 \%$ in people with normal weight to $21.5 \%$ in those with obesity and from $10.3 \%$ in people with normal WC to $24.1 \%$ in those with abnormal WC (Table 2). Similarly, the prevalence of hypertension increased from $13.7 \%$ to $35.4 \%$ in participants with obesity and from $16.7 \%$ to $35.7 \%$ in those with central obesity. The corresponding values for diabetes changed from $7.0 \%$ to $11.6 \%$ for participants with obesity and from $7.7 \%$ to $12.8 \%$ for central obesity in phase 1 (13). With regard to hypertension, these values were $22.6 \%$ to $37.4 \%$ for participants with obesity and $16.5 \%$ to $40.9 \%$ for those with central obesity in phase 1 (13). Almost all values were higher in phase 2 compared to phase 1 . Hypercholesterolaemia and hypertriglyceridaemia were also important comorbidities accompanying overweight, obesity and central obesity (Table 2).

\section{Incidence rate of overweight, obesity and central obesity}

Overall, the 5-year incidence rate (persons per 100 person-years) was 5.5 for overweight, 4.7 for obesity and 2.9 for central obesity (Table 3). The lowest incidence rate of obesity belonged to those who were dependent opium users, while the highest incidence rate of obesity was in the age group of 25-34 years. Higher incidence rates of overweight, obesity and central obesity were observed in women compared to men. Also, people in the age group of 35-44 years had the highest incidence rate of over- 
Table 1 Standardized prevalence of OW, OB and COB, and AOR for different associated factors in adults in Kerman, Islamic Republic of Iran

\begin{tabular}{|c|c|c|c|c|c|c|c|c|c|}
\hline Subgroup & $\begin{array}{c}\text { OW } \\
\%(95 \% \mathrm{CI})\end{array}$ & $\begin{array}{c}\text { OB } \\
\%(95 \% \mathrm{CI})\end{array}$ & $\mathbf{P}$ & $\begin{array}{c}\text { COB } \\
\%(95 \% \mathrm{CI})\end{array}$ & $\mathbf{P}$ & $\begin{array}{c}\text { OW/OB } \\
\operatorname{AOR}(95 \% \mathrm{CI})\end{array}$ & $\boldsymbol{P}$ & $\begin{array}{c}\text { COB } \\
\operatorname{AOR}(95 \% \mathrm{CI})\end{array}$ & $\mathbf{P}$ \\
\hline Overall & $35.8(34.7-36.8)$ & $22.3(21.4-23.2)$ & & $31.1(30.1-32.0)$ & & - & & - & \\
\hline \multicolumn{10}{|l|}{ Sex } \\
\hline Men & $37.0(35.3-38.6)$ & $16.0(14.7-17.3)$ & $<0.001$ & $15.6(14.4-16.8)$ & $<0.001$ & 1 & & 1 & \\
\hline Women & $35.0(33.6-36.4)$ & $26.3(25.2-27.5)$ & & $41.2(39.9-42.5)$ & & $1.4(1.3-1.6)$ & $<0.001$ & $4.6(4.1-5.1)$ & $<0.001$ \\
\hline \multicolumn{10}{|l|}{ Age group (yr) } \\
\hline $15-24$ & $20.6(18.7-22.4)$ & $10.3(8.9-11.7)$ & $<0.001$ & $10.9(9.5-12.4)$ & $<0.001$ & 1 & & 1 & \\
\hline $25-34$ & $36.2(34.6-37.8)$ & $18.0(16.7-19.3)$ & & $23.4(22.0-24.8)$ & & $2.8(2.4-3.2)$ & $<0.001$ & $2.6(2.1-3.3)$ & $<0.001$ \\
\hline $35-44$ & $42.6(41.1-44.2)$ & $26.7(25.4-28.1)$ & & $36.2(34.7-37.6)$ & & $6.1(5.2-7.1)$ & $<0.001$ & $4.8(3.8-5.9)$ & $<0.001$ \\
\hline $45-54$ & $43.6(42.0-45.1)$ & $31.0(29.6-32.4)$ & & $42.6(41.1-44.0)$ & & $7.4(6.3-8.6)$ & $<0.001$ & $6.1(4.9-7.6)$ & $<0.001$ \\
\hline $55-64$ & $40.2(38.7-41.7)$ & $31.9(30.4-33.3)$ & & $48.4(47.0-49.9)$ & & $5.8(4.9-6.8)$ & $<0.001$ & $6.8(5.4-8.5)$ & $<0.001$ \\
\hline $65-75$ & $40.8(38.9-42.7)$ & $22.6(21.0-24.2)$ & & $41.9(40.1-43.7)$ & & $3.4(2.8-4.1)$ & $<0.001$ & $4.4(3.4-5.7)$ & $<0.001$ \\
\hline \multicolumn{10}{|l|}{ Education } \\
\hline Illiterate & $36.1(17.2-55.0)$ & $31.8(13.9-49.6)$ & $<0.001$ & $43.6(24.6-62.7)$ & $<0.001$ & 1 & & 1 & \\
\hline $\begin{array}{l}\text { Primary to } \\
\text { high school }\end{array}$ & $34.8(33.6-36.0)$ & $23.5(22.5-24.6)$ & & $32.5(31.3-33.6)$ & & $1.5(1.3-1.7)$ & $<0.001$ & $0.93(0.81-1.06)$ & 0.304 \\
\hline $\begin{array}{l}\text { Above high } \\
\text { school }\end{array}$ & $40.4(38.2-42.6)$ & $19.1(17.3-20.8)$ & & $24.7(22.9-26.6)$ & & $1.7(1.4-2.0)$ & $<0.001$ & $0.75(0.63-0.89)$ & $<0.001$ \\
\hline \multicolumn{10}{|l|}{$\begin{array}{l}\text { Current cigarette } \\
\text { smoker }\end{array}$} \\
\hline No & $36.1(35.0-37.1)$ & $23.3(22.4-24.2)$ & $<0.001$ & $32.8(31.8-33.8)$ & $<0.001$ & 1 & & 1 & \\
\hline Yes & $35.9(30.7-41.1)$ & $14.1(10.4-17.8)$ & & $15.2(11.5-18.8)$ & & $0.55(0.48-0.62)$ & $<0.001$ & $0.7(0.58-0.84)$ & $<0.001$ \\
\hline \multicolumn{10}{|l|}{ Opium use } \\
\hline No & $36.2(35.1-37.3)$ & $23.5(22.6-24.4)$ & $<0.001$ & $33.2(32.2-34.2)$ & $<0.001$ & 1 & & 1 & \\
\hline Occasional & $35.0(28.6-41.3)$ & $14.6(12.0-17.3)$ & & $17.0(14.2-19.7)$ & & $0.65(0.57-0.73)$ & $<0.001$ & $0.78(0.68-0.90)$ & 0.001 \\
\hline Dependent & $35.0(28.1-41.8)$ & $19.4(12.0-26.7)$ & & $22.0(15.7-28.3)$ & & $0.79(0.64-0.97)$ & 0.025 & $1.2(0.98-1.6)$ & 0.064 \\
\hline \multicolumn{10}{|l|}{ Depression } \\
\hline No & $36.3(35.2-37.5)$ & $21.9(21.0-22.9)$ & $<0.001$ & $30.5(29.5-31.5)$ & 0.01 & 1 & & 1 & \\
\hline Yes & $33.2(30.5-35.9)$ & $24.3(22.0-26.5)$ & & $34.2(31.6-36.7)$ & & $0.87(0.79-0.96)$ & 0.005 & $0.94(0.85-1.0$ & 0.246 \\
\hline \multicolumn{10}{|l|}{ Anxiety } \\
\hline No & $35.4(34.1-36.8)$ & $21.2(20.1-22.4)$ & $<0.001$ & $29.1(27.9-30.3)$ & $<0.001$ & 1 & & 1 & \\
\hline Yes & $36.3(34.7-38.0)$ & $23.8(22.4-25.1)$ & & $33.8(32.4-35.3)$ & & $1.1(1.0-1.2)$ & 0.004 & $1.0(0.94-1.1)$ & 0.47 \\
\hline \multicolumn{10}{|l|}{ Diabetes } \\
\hline Normal & $35.1(34.0-36.3)$ & $19.8(18.9-20.8)$ & $<0.001$ & $27.3(26.3-28.4)$ & $<0.001$ & 1 & & 1 & \\
\hline Prediabetes & $38.9(35.3-424)$ & $29.0(25.8-32.3)$ & & $38.7(35.5-41.9)$ & & $1.8(1.6-2.0)$ & $<0.001$ & $1.7(1.6-1.9)$ & $<0.001$ \\
\hline Diabetes & $33.4(25.7-41.1)$ & $38.7(29.6-47.7)$ & & $51.5(41.9-61.2)$ & & $1.8(1.6-2.1)$ & $<0.001$ & $2.0(1.8-2.3)$ & $<0.001$ \\
\hline \multicolumn{10}{|l|}{ Hypertension } \\
\hline Normal & $35.7(34.6-36.7)$ & $20.0(19.1-20.9)$ & $<0.001$ & $28.6(27.6-29.6)$ & $<0.001$ & 1 & & 1 & \\
\hline Hypertension & $35.4(25.1-45.6)$ & $46.5(35.0-58.1)$ & & $51.3(39.8-62.8)$ & & $2.0(1.7-2.2)$ & $<0.001$ & $1.8(1.6-2.0)$ & $<0.001$ \\
\hline \multicolumn{10}{|l|}{ Physical activity } \\
\hline Low & $36.2(34.6-37.7)$ & $22.5(21.3-23.8)$ & & $31.5(30.1-32.9)$ & & 1 & & 1 & \\
\hline Moderate & $36.1(34.4-37.9)$ & $23.5(22.0-24.9)$ & $<0.001$ & $33.5(31.9-35.1)$ & $<0.001$ & $1.1(1.0-1.3)$ & 0.016 & $1.1(0.95-1.2)$ & 0.174 \\
\hline High & $32.9(30.4-35.3)$ & $17.8(15.7-19.8)$ & & $21.8(19.7-24.0)$ & & $1.3(1.1-1.4)$ & $<0.001$ & $1.2(1.0-1.4)$ & 0.005 \\
\hline
\end{tabular}

Data from Kerman Coronary Artery Disease Risk Factors Study phase 2, $n=9997,2014-2018 . A O R=$ adjusted odds ratio; $C I=$ confidence interval; $C O B=$ central obesity; $O B=$ obesity; OW = overweight.

weight. Cigarette smokers and opium users had a lower incidence rate of overweight and obesity. Also, there was a reverse relationship between the level of physical activity and incidence rates of overweight, obesity and central obesity; i.e., the people with high physical activity had lower incidence rate of overweight, obesity and central obesity. 
Figure 1 Body mass index (BMI) and waist circumference (WC) values (mean \pm SD) of the participants in the study by sex (A, B) and age group (C, D). Total participants $=9997$ in phase 2 and 5900 in phase 1 . The data of phase 1 were used here for comparison and are extracted from our paper published previously (13).
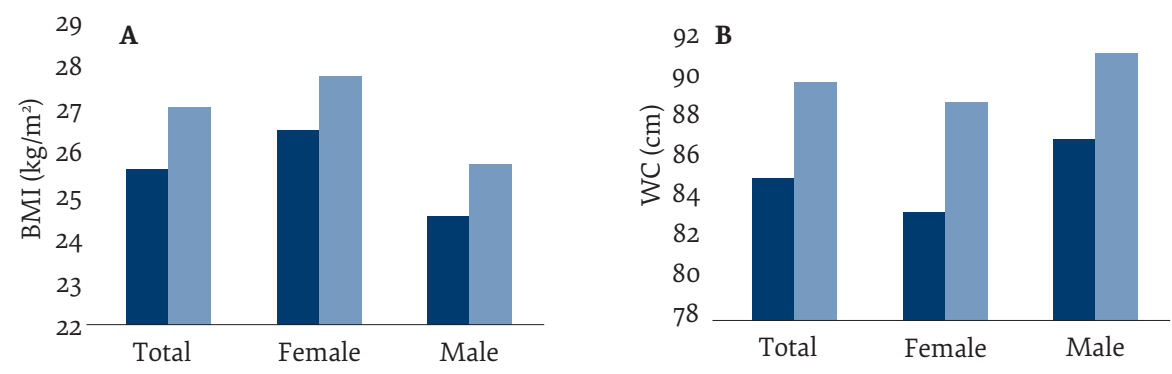

C

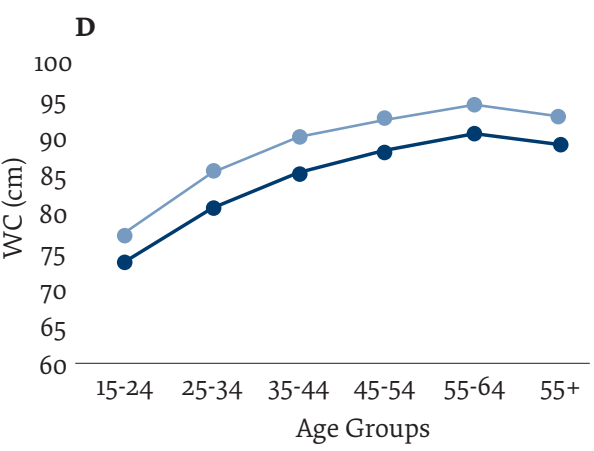

\section{Discussion}

The findings of this study showed that currently one fourth to one third of the population in Southeastern Iran was overweight, obesity or central obesity, which were all significantly more prevalent in phase 2 compared to phase 1 . These measures show a high current prevalence

and a sharp rise in the prevalence of these unsafe metabolic variables during the 5-year period. In addition, all of the measures were higher in women than in men. People with low physical activity had a high incidence rate and those with high physical activity had a low incidence rate. Middle-aged people had the highest incidence of overweight, obesity and central obesity.

Figure 2 Prevalence of overweight, obesity and central obesity in the participants by sex (A-C) and age (D-F) (total participants = 9997). The data of phase $1(n=5900)$ were used here for comparison and are extracted from our paper published previously (13).
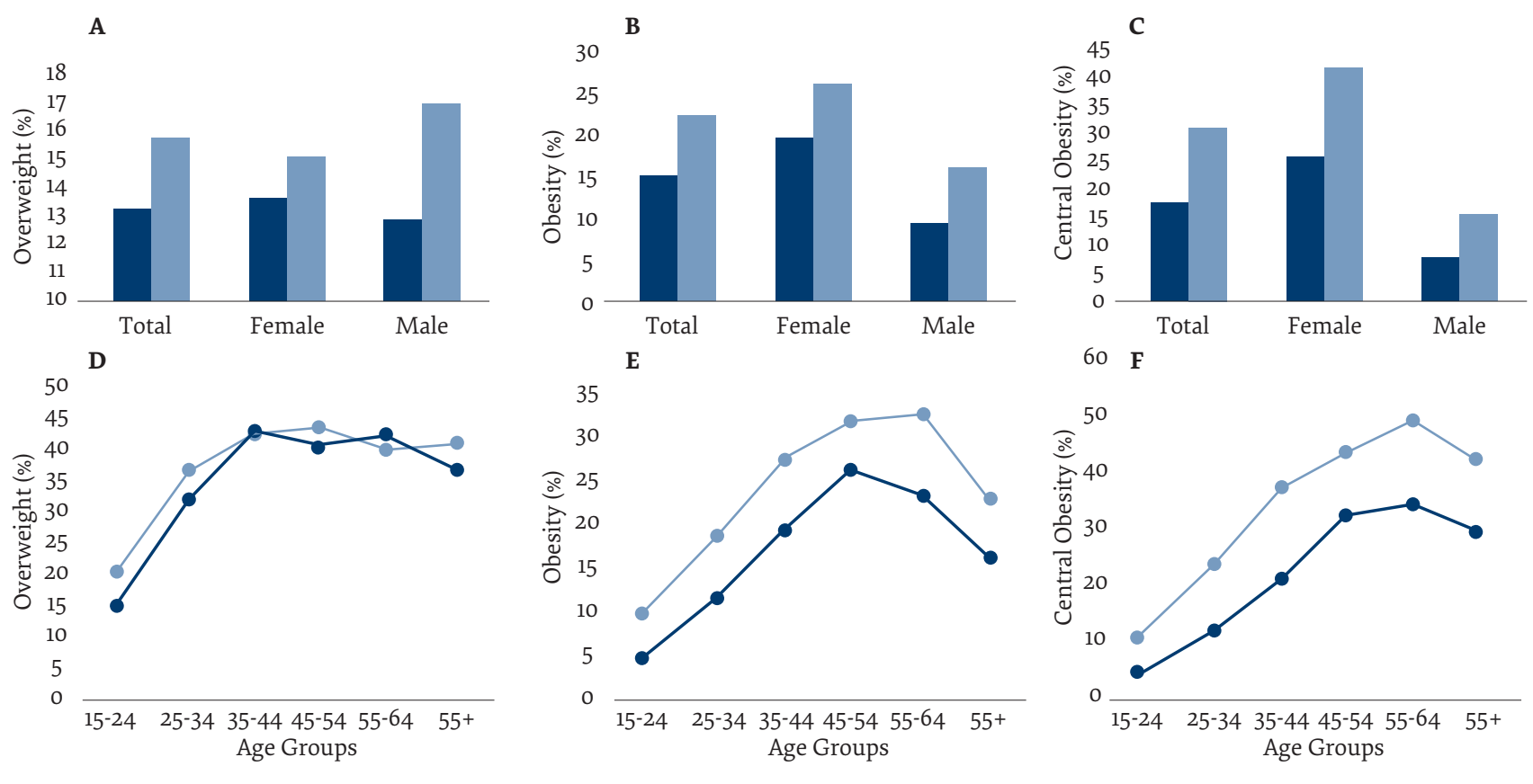

Phase 1 Phase 2 
Table 2 Prevalence of different comorbidities according to BMI and WC categories in adults in Kerman, Islamic Republic of Iran

\begin{tabular}{|c|c|c|c|c|c|}
\hline Comorbidities & $\begin{array}{l}\text { Normal weight } \\
\%(95 \% \mathrm{CI})\end{array}$ & $\begin{array}{l}\text { Overweight } \\
\%(95 \% \text { CI })\end{array}$ & $\begin{array}{c}\text { Obesity } \\
\%(95 \% \text { CI })\end{array}$ & $\begin{array}{l}\text { Normal WC } \\
\%(95 \% \mathrm{CI})\end{array}$ & $\begin{array}{c}\text { Inappropriate WC } \\
\%(95 \% \mathrm{CI})\end{array}$ \\
\hline Diabetes mellitus & $9.1(8.4-9.9)$ & $16.7(15.7-17.7)$ & $21.5(20.2-23.0)$ & $10.3(9.8-10.9)$ & $24.1(23.0-25.3)$ \\
\hline Hypertension & $13.7(12.8-14.5)$ & $24.9(23.8-26.0)$ & $35.4(33.8-36.9)$ & $16.7(16.0-17.4)$ & $35.7(34.4-37.1)$ \\
\hline Hypercholesterolaemia & $13.8(12.9-14.7)$ & $25.3(24.2-26.4)$ & $31.0(29.5-32.5)$ & $16.8(16.1-17.5)$ & $33.2(31.9-34.5)$ \\
\hline Hypertriglyceridaemia & $24.4(23.3-25.4)$ & $47.6(46.3-48.9)$ & $51.8(50.2-53.4)$ & $33.2(32.3-34.1)$ & $52.7(51.3-54.0)$ \\
\hline Depression & $25.6(24.5-26.7)$ & $22.8(21.7-23.9)$ & $26.4(25.0-27.8)$ & $23.9(23.1-24.7)$ & $25.9(24.7-27.2)$ \\
\hline Anxiety & $54.8(53.5-56.0)$ & $53.1(51.9-54.4)$ & $55.4(53.8-57.0)$ & $54.0(53.1-55.0)$ & $59.4(58.0-60.7)$ \\
\hline
\end{tabular}

Data from Kerman Coronary Artery Disease Risk Factors Study; $n=15,897$ ), 2009-2011 (phase 1) and 2014-2018 (phase 2). Normal weight $=B M I<25 \mathrm{~kg} / \mathrm{m2} ;$ overweight $=25 \leq B M I<30 \mathrm{~kg} /$ $\mathrm{mz}$; and obese $=B M I \geq 30 \mathrm{~kg} / \mathrm{mz}$. Inappropriate $\mathrm{WC}$ (central obesity) was defined as $>88 \mathrm{~cm}$ for women and $>102 \mathrm{~cm}$ for men. BMI $=$ body mass index; $C I=$ confidence interval; $W C=$ waist circumference.

In a recent systematic review, in subnational studies, the prevalence of overweight and obesity among adults ranged from $12.8 \%$ to $76.4 \%$ and from $2.4 \%$ to $35.4 \%$, respectively, while in national studies, it was reported as
$27.0-38.5 \%$ and $12.6-25.9 \%$, respectively (12). There was a significant relationship between the 2 baseline variables of female gender and age and occurrence of overweight and obesity. The authors believe that the main reasons

\begin{tabular}{|c|c|c|c|c|c|c|}
\hline Subgroup & $\begin{array}{c}\text { No. with } \\
\text { OW }\end{array}$ & $\begin{array}{c}\text { Incidence rate of } \\
\text { OW } \\
(95 \% \mathrm{CI})\end{array}$ & $\begin{array}{l}\text { No. with } \\
\text { OB }\end{array}$ & $\begin{array}{c}\text { Incidence rate of } \\
\text { OB } \\
(95 \% \mathrm{CI})\end{array}$ & $\begin{array}{l}\text { No. with } \\
\text { COB }\end{array}$ & $\begin{array}{c}\text { Incidence rate of } \\
\text { COB } \\
(95 \% \mathrm{CI})\end{array}$ \\
\hline Overall & 346 & $5.5(4.9-6.1)$ & 271 & $4.7(4.2-5.3)$ & 336 & $2.9(2.6-3.2)$ \\
\hline \multicolumn{7}{|l|}{ Sex } \\
\hline Male & 166 & $4.7(4.0-5.5)$ & 97 & $3.6(2.9-4.4)$ & 98 & $1.5(1.2-1.9)$ \\
\hline Female & 179 & $6.4(5.5-7.4)$ & 173 & $5.7(4.96 .6)$ & 238 & $4.5(3.9-5.1)$ \\
\hline \multicolumn{7}{|l|}{ Age group (yr) } \\
\hline $15-24$ & 49 & $4.2(3.1-5.5)$ & 12 & $5.2(2.7-8.9)$ & 17 & $1.1(0.6-1.8)$ \\
\hline $25-34$ & 85 & $6.6(5.3-8.2)$ & 51 & $7.0(\mid 5.2-9.1)$ & 53 & $2.6(1.9-3.4)$ \\
\hline $35-44$ & 76 & $7.3(5.8-9.1)$ & 59 & $4.8(3.6-6.1)$ & 70 & $3.1(2.4-3.9)$ \\
\hline $45-54$ & 60 & $6.0(4.6-7.6)$ & 78 & $4.9(3.9-6.1)$ & 95 & $3.8(3.1-4.7)$ \\
\hline $55-64$ & 55 & $5.3(4.0-6.8)$ & 54 & $4.2(3.2-5.5)$ & 68 & $3.3(2.6-4.2)$ \\
\hline $65-75$ & 21 & $2.5(1.7-4.1)$ & 18 & $2.8(1.6-4.2)$ & 33 & $2.5(1.7-3.5)$ \\
\hline \multicolumn{7}{|c|}{ Cigarette smoker } \\
\hline No & 311 & $5.7(5.1-6.4)$ & 249 & $4.7(4.1-5.3)$ & 316 & $3.1(2.7-3.4)$ \\
\hline Yes & 35 & $3.8(2.7-5.3)$ & 21 & $4.8(3.0-7.3)$ & 20 & $1.5(0.9-2.3)$ \\
\hline \multicolumn{7}{|l|}{ Opium use } \\
\hline No & 286 & $5.8(5.1-6.5)$ & 240 & $4.9(4.3-5.5)$ & 302 & $3.2(2.8-3.5)$ \\
\hline Occasional & 51 & $4.6(3.4-6.0)$ & 26 & $3.7(2.4-5.5)$ & 30 & $1.7(1.1-2.4)$ \\
\hline Dependent & 9 & $3.7(1.7-7.0)$ & 4 & $3.6(1.0-9.1)$ & 4 & $1.1(0.3-2.8)$ \\
\hline \multicolumn{7}{|l|}{ Depression } \\
\hline No & 223 & $5.5(4.8-6.3)$ & 173 & $4.7(4.0-5.5)$ & 195 & $2.5(2.2-2.9)$ \\
\hline Yes & 120 & $5.4(4.5-6.4)$ & 93 & $4.6(3.7-5.6)$ & 138 & $3.5(3.0-4.2)$ \\
\hline \multicolumn{7}{|l|}{ Anxiety } \\
\hline No & 85 & $4.8(3.9-6.0)$ & 62 & $4.6(3.5-5.8)$ & 68 & $2.2(1.7-2.8)$ \\
\hline Yes & 261 & $5.7(5.1-6.4)$ & 200 & $4.6(4.0-5.2)$ & 268 & $3.1(2.8-3.5)$ \\
\hline \multicolumn{7}{|l|}{ Physical activity } \\
\hline Low & 143 & $5.4(4.6-6.4)$ & 115 & $4.8(4.0-5.8)$ & 152 & $3.0(2.6-3.6)$ \\
\hline Moderate & 170 & $5.7(4.8-6.5)$ & 136 & $4.7(3.9-5.5)$ & 161 & $2.9(2.5-3.4)$ \\
\hline High & 33 & $4.9(3.7-6.8)$ & 19 & $4.3(2.6-6.7)$ & 23 & $2.1(1.3-3.2)$ \\
\hline
\end{tabular}

Data from Kerman Coronary Artery Disease Risk Factors Study, phase 2, 2014-2018, $n=9997)$. CI = confidence interval; $C O B=$ central obesity; $O B=$ obesity; $O W=$ overweight 
for the higher prevalence of obesity in these baseline subgroups included improper lifestyle such as low physical activity and tendency towards unhealthy dietary habits. The data obtained in phase 1 showed that low physical activity was significantly higher in women (15). The global prevalence of obesity is greater in women compared with men (18). Most of the studies in the Islamic Republic of Iran have shown higher prevalence of overweight and obesity among women $(9,13,19,20)$, and low physical activity could be one of the main reasons for this difference between men and women $(15,21)$. According to our study published in $2016,16.9 \%$ of women and $9.3 \%$ of men were classified as obese and $7.5 \%$ of men and $21.5 \%$ of women were reported as overweight (13). A study by Saadatifar et al. (9) showed that the prevalence of obesity was $12.3 \%$ in men and $18.9 \%$ in women in Northeastern Iran. In a nationwide study by Janghorbani et al. (22), the age-adjusted prevalence of overweight and obesity was $42.8 \%$ and $11.1 \%$ in men and $57.0 \%$ and $25.2 \%$ in women, respectively. In this regard, advanced age, low physical activity, low education, marriage, and urban residence were strongly associated with obesity (22).

The prevalence of hypertension in participants with obesity was about 3 times that of normal-weight individuals. Also, the prevalence of diabetes in those with obesity/central obesity was more than double that of individuals with normal weight. Corresponding values for both diabetes and hypertension were about 1.5 times higher than those in phase 1 of the study (13). These findings show that obesity steeply increases the risk of other CAD risk factors, and this association has increased in the community during the 5-year interval between the 2 phases of the study.

Prevalence of overweight and obesity decreased with education level. This may be explained by the fact that those with a higher socioeconomic status have more appropriate lifestyle regarding daily activities and dietary behaviour, as well as a lower tendency towards smoking and alcohol consumption. Cutler and Lleras-Muney found that people with more years of schooling are less likely to smoke, consume excess alcohol, be overweight or obese, or use illegal drugs (23). In addition, the moreeducated individuals are more likely to exercise. In the study by Veghari et al. in Isfahan, the risk of central obesity increased in illiterate people (24).

Cigarette smokers had a lower prevalence of overweight and obesity in our study. It has been shown that nicotine greatly increases energy expenditure, and it could reduce appetite, which could explain why smokers tend to have lower body weight (25). In terms of opium consumption, we found that the prevalence of obesity in dependent opium users was lower than it was in nonusers. Our previous study in diabetic patients also revealed lower BMI and prevalence of overweight and obesity in opium addicts compared to nonaddicted people (26).

People with higher physical activity had lower incidence of overweight, obesity and central obesity, and those with lower physical activity had higher incidence of overweight, obesity and central obesity. It has also been reported that low physical activity is associated with hypertension, high cholesterol and high triglyceride (27).

Overall, the rapid increase in the rate of overweight and obesity during the past 5 years, especially in women who are less physically active, predisposes the population to $\mathrm{CAD}$, which is already a major health problem in the region. This risk profile may significantly increase the burden of CVD in the community in the near future if left unaddressed.

Our study had 2 limitations. First, we lost $52 \%$ of the participants from phase 1 and were not able to assess the effects of this on incidence rate. The time interval between phase 1 and 2 was 5 years and for incidence rate calculation (the denominator), for those who were lost to follow-up, we assumed they had been lost midway (16). Second, our study was conducted in Southern Iran, which may limit our ability to generalize our findings to the whole nation.

\section{Conclusion}

Overall, overweight and obesity affected almost $60 \%$ of the participants, and were major public health problems, with a significantly higher prevalence and incidence rate in women, middle aged people, illiterate and less physically active individuals. Obesity increases the risk of other CAD risk factors (e.g., diabetes, hypertension and dyslipidaemia) and this association has increased during the last 5 years. Therefore, it is necessary to assess the efficacy of local and national intervention programmes in managing and controlling the epidemic of overweight/ obesity and the consequent rise in CVD in Southeastern Iran.

\section{Acknowledgement}

We would like to extend our gratitude to the Deputy for Research and Technology at Kerman University of Medical Sciences for funding the study (Grant no 93/310KA).

Funding: None.

Competing interests: None declared. 


\section{Point épidémiologique sur la prévalence et l'incidence du surpoids et de l'obésité chez les adultes dans le sud-est de la République islamique d'Iran : résultats de l'étude KERCADR (Kerman Coronary Artery Disease Risk Factors Study)}

\section{Résumé}

Contexte : L'obésité est un phénomène répandu dans le monde entier, notamment dans les pays à revenu faible et intermédiaire.

Objectifs : Mettre à jour les données sur la prévalence du surpoids, de l'obésité et de l'obésité centrale et mesurer les taux d'incidence de ces résultats chez les adultes vivant dans le sud-est de la République islamique d'Iran.

Méthodes : Nous avons recruté 9997 adultes (âgés de 15 à 80 ans) entre 2014 et 2018 (phase 2), dont 2820 avaient participé à la phase 1 (2009-2011). Les participants ont été examinés afin de détecter le surpoids, l'obésité, l'obésité centrale, un diabète, une hypertension, un manque d'activité physique et une dyslipidémie. Des modèles de régression logistique univariés et multivariés ont été utilisés pour déterminer les facteurs prédictifs potentiels du surpoids, de l'obésité et de l'obésité centrale, et ont permis d'obtenir des odds ratio ajustés (ORa). Le taux d'incidence du surpoids, de l'obésité et de l'obésité centrale a été rapporté parmi ceux qui n'ont présenté aucun de ces résultats lors de la phase 1.

Résultats : La prévalence était de 35,8\% (37\% chez les hommes, $35 \%$ chez les femmes) pour le surpoids, de $22,3 \%$ (16\% chez les hommes, $26,3 \%$ chez les femmes) pour l'obésité et de 31,1\% (15,6\% chez les hommes, 41,2 \% chez les femmes) pour l'obésité centrale. La prévalence du surpoids/de l'obésité était significativement associée à l'âge $(\mathrm{ORa}=2,8$ à 7,4), à un niveau d'éducation supérieur ( $\mathrm{ORa}=1,7)$, au sexe féminin $(\mathrm{ORa}=1,4)$, à une faible activité physique $(\mathrm{ORa}=1,3)$, au tabagisme $(\mathrm{ORa}=0,55)$ et à la consommation d'opium $(\mathrm{ORa}=0,79)$. La prévalence est passée de $33,3 \%$ à 35,8\% pour le surpoids et de 15,4\% à 22,3\% pour l'obésité entre les phases 1 et 2 . Le taux d'incidence pour 100 personnes-années était de 5,5 pour le surpoids, 4,7 pour l'obésité et 2,9 pour l'obésité centrale.

Conclusion : La prévalence du surpoids et de l'obésité a augmenté sur une période de cinq ans. Les participants d'âge moyen, les femmes et ceux qui avaient une faible activité physique présentaient un risque plus élevé de surpoids ou d'obésité.

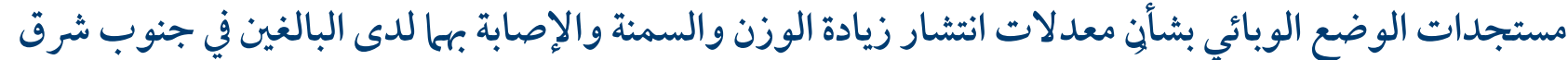

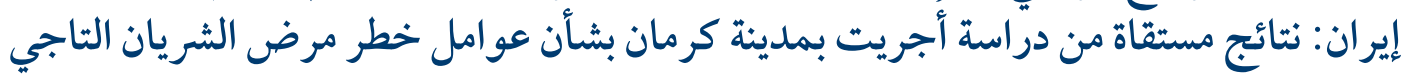

$$
\begin{aligned}
& \text { حميد نجفيبور، مهدي باغري، شادان صابري، ميترا شادكام فاروقي، راحله أمير زاده، علي ميرزازاده }
\end{aligned}
$$

$$
\begin{aligned}
& \text { الخلفية: تنتشر السمنة في جميع أنحاء العالم، لا سيَّما في البلدان المنخفضة والمتو سطة الدخل. }
\end{aligned}
$$

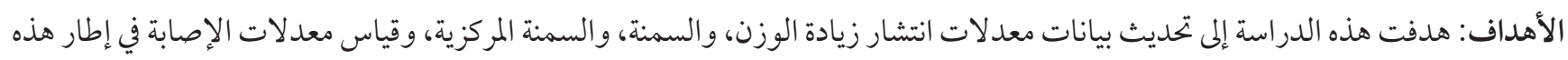

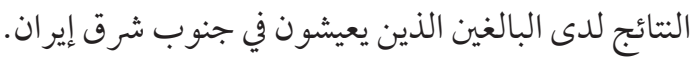

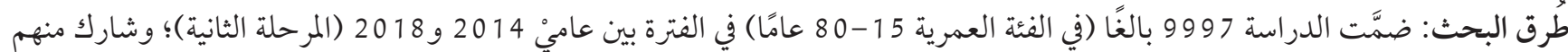

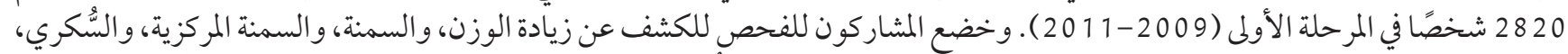

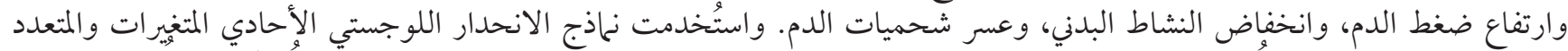

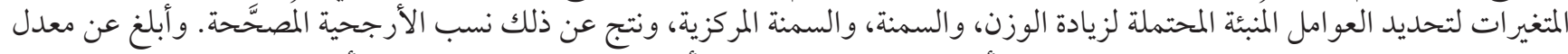

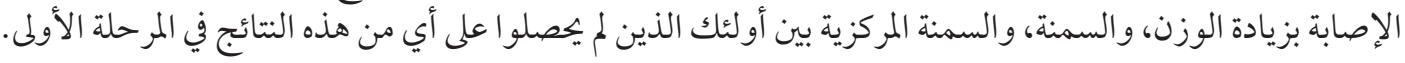

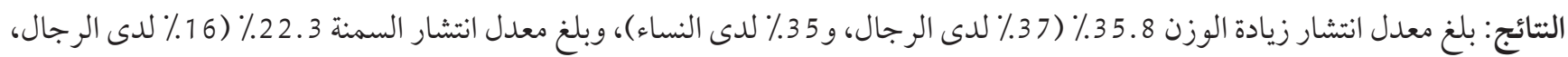

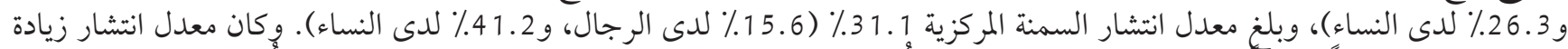

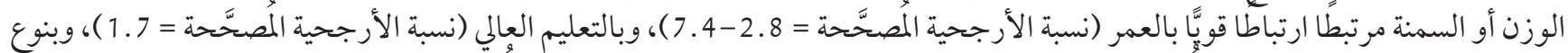

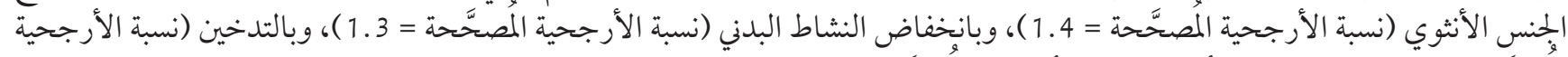

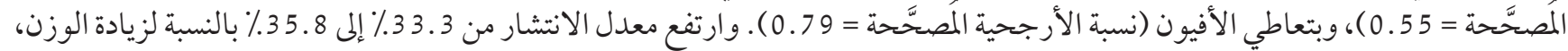

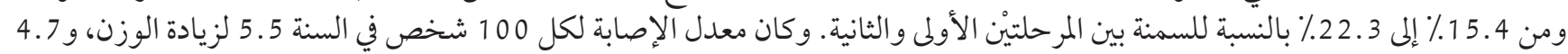
للسمنة، و 2.9 للسمنة المركزية.

الاستنتاجات: ازداد معدل انتشار زيادة الوزن والسمنة على مدى 5 سنوات. وكان المشاركون في منتصف العمر و النساء والأشخاص من ذوي

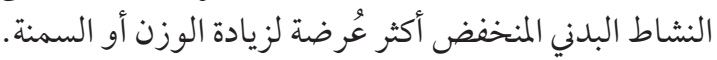




\section{References}

1. Morgen CS, Sorensen TI. Obesity: global trends in the prevalence of overweight and obesity. Nat Rev Endocrinol. 2014 Sep;10(9):513-4. https://doi.org/10.1038/nrendo.2014.124 PMID:25048038

2. Abarca-Gómez L, Abdeen ZA, Hamid ZA, MAbu-Rmeileh N, Acosta-Cazares B, Acuin C, et al. Worldwide trends in body-mass index, underweight, overweight, and obesity from 1975 to 2016: a pooled analysis of 2416 population-based measurement studies in 128.9 million children, adolescents, and adults. Lancet. 2017 Dec 16;390(10113):2627-42. https://doi.org/10.1016/So1406736(17)32129-3 PMID:29029897

3. Matsuda M, Shimomura I. Increased oxidative stress in obesity: implications for metabolic syndrome, diabetes, hypertension, dyslipidemia, atherosclerosis, and cancer. Obes Res Clin Pract. 2013 Sep-Oct;7(5):e330-41. https://doi.org/10.1016/j. orcp.2013.05.004 PMID:2445576

4. Obesity and overweight [website]. Geneva: World Health Organization; 2021 (https://www.who.int/news-room/fact-sheets/detail/obesity-and-overweight, accessed 19 April 2021).

5. Jones-Smith JC, Gordon-Larsen P, Siddiqi A, Popkin BM. Is the burden of overweight shifting to the poor across the globe? Time trends among women in 39 low-and middle-income countries (1991-2008). Int J Obes. 2012 Aug;36:1114-20. https://doi. org/10.1038/ijo.2011.179 PMID:21912397

6. Shi X, He S, Tao Y, Wang C, Jiang Y, Feng X, et al. Prevalence of obesity and associated risk factors in Northeastern China. Diabetes Res Clin Pract 2011 Mar;91(3):389-94. https://doi.org/10.1016/j.diabres.2010.11.002 PMID:21130515

7. Eftekhari MH, Nikookar S, Tabatabaei H, Zahedani MR. GW27-eoog6 Overweight and obesity and their associated factors in adult women referring to medical and health centers in Shiraz, Iran. J Am Coll Cardiol. 2016;68(16 Supplement):C182-3.

8. Farrag NS, Cheskin LJ, and Farag M K. A systematic review of childhood obesity in the Middle East and North Africa (MENA) region: prevalence and risk factors meta-analysis. Adv Pediatr Res. 2017;4:8. https://doi.org/10.12715/apr.2017.4.8 PMID:29354689

9. Saadatifar H, Ostadimoghaddam H, Khoshhal F, Jabbari-Azad F, Mohazzab-Torabi S, Yekta A, et al. The prevalence of obesity and overweight in Northeastern Iran. Asian J Med Sci. 2018 Jun 9;4(1):1-10. https://doi.org/10.15419/ajhs.v4i1.435

10. Mohammadpour-Ahranjani B, Pallan M, Rashidi A, Adab P. Contributors to childhood obesity in Iran: the views of parents and school staff. J. Public Health. 2014 Jan;128(1):83-90. https://doi.org/10.1016/j.puhe.2013.10.005 PMID:24332408

11. Esteghamati A, Khalilzadeh O, Mohammad K, Meysamie A, Rashidi A, Kamgar M, et al. Secular trends of obesity in Iran between 1999 and 2007: National Surveys of Risk Factors of Non-Communicable Diseases. Metab Syndr Relat Disord. 2010 Jun;8(3):20913. https://doi.org/10.1089/met.2009.0064 PMID:20085488

12. Jafari-Adli S, Jouyandeh Z, Qorbani M, Soroush A, Larijani B, Hasani-Ranjbar S. Prevalence of obesity and overweight in adults and children in Iran; a systematic review. J Diabetes Metab Disord. 2014 Dec 23;13(1):121. https://doi.org/10.1186/s40200-014-0121-2 PMID:25610814

13. Najafipour H, Yousefzadeh G, Forood A, Karamouzian M, Shadkam M, Mirzazadeh A. Overweight and obesity prevalence and its predictors in a general population: A community-based study in Kerman, Iran (Kerman coronary artery diseases risk factors studies). ARYA Atheroscler. 2016 Jan;12(1):18-27. PMID: 27114733

14. Najafipour H, Mirzazadeh A, Haghdoost A, Shadkam M, Afshari M, Moazenzadeh M, et al. Coronary Artery Disease Risk Factors in an Urban and Peri-urban Setting, Kerman, Southeastern Iran (KERCADR Study): methodology and preliminary report. Iran J Public Health. 2012;41(9):86-92. PMID:23193513

15. Najafipour H, Moazenzadeh M, Afshari M, Nasri HR, Khaksari M, Forood A, et al. The prevalence of low physical activity in an urban population and its relationship with other cardiovascular risk factors: Findings of a community-based study (KERCADRS) in southeast of Iran ARYA Atheroscler. 2016 Sep;12(5):212-9. PMID:28458695

16. Principles of epidemiology in public health practice. An introduction to applied epidemiology and biostatistics, third edition. Lesson 3: measures of risk. Atlanta: Centers for Disease Control and Prevention; 2012

17. Introduction to survey data analysis. Statistical Consulting Group. University of California, Los Angeles; 2015 (http://www.ats. ucla.edu/stat/seminars/svy_intro).

18. Garawi F, Devries K, Thorogood N, Uauy R. Global differences between women and men in the prevalence of obesity: is there an association with gender inequality? Eur J Clin Nutr. 2014 Oct;68(10):1101-6. https://doi.org/10.1038/ejcn.2014.86 PMID:24918120

19. Hosseinpanah F, Barzin M, Eskandary PS, Mirmiran P, Azizi F. Trends of obesity and abdominal obesity in Tehranian adults: a cohort study. BMC Public Health. 2009 Nov 23;9:426. https://doi.org/10.1186/1471-2458-9-426 PMID:19930614

20. Kelishadi R, Alikhani S, Delavari A, Alaedini F, Safaie A, Hojatzadeh E (2008) Obesity and associated lifestyle behaviors in Iran: findings from the first national noncommunicable disease risk factor surveillance survey. Public Health Nutr. 2008 Mar;11(3):246-51. https://doi.org/10.1017/S1368980007000262 PMID:17625028

21. Talaei M, Rabiei K, Talaei Z, Amiri N, Zolfaghari B, Kabiri P, et al. Physical activity, sex, and socioeconomic status: a population based study. ARYA Atheroscler. 2013 Jan;9(1):51-60. PMID: 3696760

22. Janghorbani M, Amini M, Willett WC, Mehdi Gouya M, Delavari A, Alikhani S, et al. First nationwide survey of prevalence of overweight, underweight, and abdominal obesity in Iranian adults. Obesity (Silver Spring) 2007 Nov;15(11):2797-808. https://doi. org/10.1038/oby.2007.332 PMID:18070771 
23. Cutler D, Lleras-Muney A. Education and health: evaluating theories and evidence. 2006 July;NBER Working Paper 12352. www. nber.org/papers/w12352

24. Veghari G, Sedaghat M, Maghsodlo S, Banihashem S, Moharloei P, Angizeh A, et al. The correlation between educational levels and central obesity in the north of Iran: an epidemiologic study ARYA Atheroscler. 2013 Jun;9(4):217-22. PMID:23970916

25. Pieroni L, Salmasi L. The effect of smoking habit changes on body weight: evidence from the UK. Econ Hum Biol. 2016 Mar;20:113. https://doi.org/10.1016/j.ehb.2015.11.002 PMID:26650917

26. Rahimi N, Gozashti MH, Najafipour H, Shokoohi M, Marefati H. Potential effect of opium consumption on controlling diabetes and some cardiovascular risk factors in diabetic patients. Addict Health. 2014 Winter;6(1-2):1-6. PMID:25140211

27. Raitakari OT, Taimela S, Porkka KV, Telama R, Valimaki I, Akerblom HK, et al. Associations between physical activity and risk factors for coronary heart disease: the Cardiovascular Risk in Young Finns Study. Med Sci Sports Exerc. 1997 Aug;29(8):1055-61. https://doi.org/10.1097/00005768-199708000-00011 PMID:9268963 